\title{
ГИСТОЛОГИЧЕСКИЕ И ГИСТОХИМИЧЕСКИЕ АСПЕКТЫ ОЦЕНКИ ОПРЕДЕЛЕНИЯ ДАВНОСТИ ВНУТРИЧЕРЕПНЫХ ГЕМАТОМ ПРИ ЧЕРЕПНО-МОЗГОВЫХ ПОВРЕЖДЕНИЯХ
}

\author{
Саркисян П.Г. , Мхитарян К.Г. \\ Начиональное бюро экспертиз, \\ Ереван, Армения
}

Нарастающая частота, высокая смертность и инвалидность черепно-мозговых травм в настоящая время является актуальной социальной проблемой и считается одним из ключевых направлений современной судебно-медицинской науки. В экспертной практике давность черепно-мозговых травм и внутричерепных гематом в основном определяется гистологическими методами исследования. Однако в ряде случаев полученные результаты не соответствуют времени получения травмы. Причинами таких неточностей при определении давности являются физическое состояние, возраст, степень разрушения вещества мозга, объем гематомы, сосудистая патология и пониженная реактивность организма пострадавщего. Отмечается, что существенным дополнением к гистологическому методу является доступный гистохимический метод трехцветной окраски фибрина. Ценность метода заключается в том, что давность повреждения определяется на ранних стадиях.

Ключевые слова: черепно-мозговая травма, внутричерепная гематома, судебно-медицинская экспертиза, давность повреждения, гистологический и гистохимический методы.

Черепно-мозговая травма является наиболее часто встречающимся повреждением и составляет приблизительно 40\% от всех видов травм [1]. В соответствии со статистикой, опубликованной Всемирной организацией здравоохранения, динамика прироста количества черепно-мозговых травм составляет примерно 2\% в год. Важно подчеркнуть, что высокая летальность и инвалидность, связанная с черепно-мозговыми травмами, на текущий момент приобретает выраженный социальный характер, безусловно, является актуальной проблемой и поэтому относится к числу ключевых направлений современной судебно-медицинской науки [2].

Черепно-мозговые травмы чаще всего встречаются у лиц наиболее активной категории населения. По данным ряда публикаций, возраст пострадавших лиц колеблется от 21 - 50 лет, а повреждения являются в большинстве своем результатом как воздействия тупых твердых предметов, так и дорожно-транспортных происшествий[3,4].

При закрытой черепно-мозговой травме случаи смертельных исходов чаще обусловлены образованием внутричерепных гематом и повреждением вещества головного мозга. При этом следует иметь в виду, что продолжительность жизни пострадавших может составлять от нескольких минут до нескольких часов и даже суток. В действительности, отталкиваясь от обобщенного практического опыта, следует подчеркнуть, не вдаваясь в подробности, что, на наш взгляд, важное значение имеют возраст, пол, обстоятельства травмы, преморбидное состояние до получения травмы, локализация гематом и их размеры. В контексте перечисленных особенностей, особого внимания заслуживают опубликованные материалы ФГАУ “Национальный

\footnotetext{
Адрес для корреспонденции: Саркисян Пётр Геворкович, эксперт отделения гистологических и химических экспертиз Отдела судебно-медицинских экспертиз Националного бюро экспертиз Республики Армения, 0004, РА, г.Ереван, пр. Адмирала Исакова, 24, Sarkisian.petr2018@ yandex.ru
} 
медицинский исследовательский центр нейрохирургии имени академика Н.Н.Бурденко” МЗ РФ, ученые которого, беря за основу результаты анализов компьютерной томографии (КТ), сфрормулировали следующие обобщенные распределения внутримозговых гематом по их локализации: лобные доли -48\%, височные -34\%, теменные -21\%, затылочные- $2 \%$, мозжечок-5\%, а также произвели разделения по размеру внутримозговой гематомы на:

-малые - максимальный диаметр в наиболее демонстративном аксиальном срезе на КТ результатах равен или больше 1,5 см и меньше 3 см (объем для сфреры составляет от 2 до15куб. $\mathrm{CM}$ );

-средние - максимальный диаметр равен или больше 3 см и меньше 4,5 см (15-45 куб. см); - большие - максимальный диаметр равен или больше 4,5 см (более 45 куб. см).

Авторы исследований упомянутого центра отмечают, что анализ компьютерных томограмм показал высокую степень корреляции между объемом и максимальным диаметром, и следовательно, ориентация на диаметр в оценке объема внутримозговых гематом, на текущий момент не только проста и удобна, но и достаточно надежна[4].

По данным других научных источников объем внутримозговых гематом колеблется от 30 до 150 мл, при этом полость гематомы нередко имеет округлую шарообразную или вытянутую форму, а травматические гематомы, наряду с этим, расположены в белом веществе полушарий обычно субкортикально - в отличие от внутримозговых гематом сосудистого генеза [5].

Следует признать, что, несмотря на непрерывно возрастающую роль гистохимических, иммуногистохимических, ультрамикроскопических и количественных методов анализа, в патоморфологии, тем не менее, основным методом морфологической диагностики давности внутричерепных гематом при черепно-мозговых травмах по-прежнему остается недорогой и нетрудоемкий качественный метод гистологического исследования[6].

Справедливости ради, следует признать, что динамика морфологических изменений в очагах ушиба и размозжения вещества головного мозга и гематом изучена достаточно полно. Так, на обширном аутопсионном материале выполнены фундаментальные исследования черепно-мозговой травмы, а на светооптическом уровне установлена и детально изучена чёткая последовательность развития в веществе головного мозга и его оболочках деструктивных травматических изменений, с реактивными и последующими репаративными тканевыми процессами [7].

В судебно-медицинской экспертной практике исключительно важным вопросом является диагностика давности внутричерепных гематом умерших людей от черепно-мозговых травм. Распространённым способом является гистологические методы диагностики. Для решения данной задачи необходимо иметь в наличии классический набор реактивов и оборудование, используемые в каждодневной практической работе гистологов. Достаточно часто для обнаружения в тканевом срезе двухвалентного железа (ферритина и гемосидерина) используется также доступный метод окраски срезов желтой кровяной солью с получением берлинской лазури синего цвета (реакции Перлса [6] или Тирман-Шмельцера [8]).

Гистологическая оценка в большинстве своем производится либо описанием исследуемых серийных гистологических срезов и анализом полученных результатов, либо используются соответствующие таблицы, где выявленные морфологические находки оцениваются по баллам. К таким таблицам в первую очередь относятся методические рекомендации, предложенные Российским научно-исследовательским нейрохирургическим институтом имени профессора А.Л. Поленова [9]. В предлагаемых методических рекомендациях впервые была сделана попытка 
представить разработанные ориентиры в виде таблиц, в которых приведена динамика макрои микроскопических признаков, связанных с временным фрактором. К каждому критерию в таблицах был дан краткий комментарий.

Несмотря на тот фракт, что данному вопросу посвящены многочисленные работы, порой противоречивого характера, тем не менее гистологический метод диагностики черепномозговых травм остается основным в практике судебно-медицинских экспертов. Однако выявляемые морфологические изменения при черепно-мозговых травмах в ряде случаев могут не соответствовать времени получения повреждений головного мозга, что может стать причиной ошибочных экспертных заключений, так как характерные гистологические признаки развиваются медленнее. Причинами таких неточностей при определении давности, по всей вероятности, являются ффизическое состояние, возраст, степень разрушения вещества мозга, объем гематомы, сосудистые патологии и пониженная реактивность организма пострадавшего. Важно отметить, что данное соображение подтверждается накопленным многолетним личным опытом практической работы[10]. При экспертных исследованиях в отдельных случаях кровоизлияний и гематом в головном мозгу после черепно-мозговых травм у ряда умерших лиц были выявлены определенные несоответствия между результатами гистологических исследований и временем наступления смерти.

Ниже, на примере из личной экспертной практики, приведем конкретный случай, когда были выбраны 6 посмертных субъектов экспертизы с внутримозговыми гематомами, у которых было точно зафиксировано время наступления смерти. Из выбранных 6 случаев у 4-х внутримозговые гематомы имели средние размеры. Диаметры гематом находились между 3 - 4,5 см. В двух остальных случаях гематомы носили обширный характер.

При гистологическом исследовании внутримозговых гематом средних размеров в 3-х случаях расхождение между морфологической картиной и временем наступления смерти находилось В интервале от 1 до 7 часов и выражалось отеком, некрозом мозговой ткани с инфильтрацией небольшого количество сегментоядерных лейкоцитов, слабой сосудистой реакцией и осаждением фибрина. Только в одном случае морфологическая картина соответствовала давности времени наступления смерти.

При обширных внутримозговых гематомах в виду того, что продолжительность жизни была короткой, гистологическая картина соответствовала времени наступления смерти.

Считаем также немаловажным поделиться накопленным опытом по определению давности в ранние периоды переломов костей, повреждения внутренних органов, внутричерепных гематом при черепно-мозговых травмах, которые также являются актуальным в судебно-медицинской практике. В последние годы внимание ряда исследователей привлекает применение селективных методов выявления динамики морфологических изменений фибрина в мягких оболочках и веществе головного мозга при острой черепно-мозговой травме. Так, в процессе изменения свойств молекул фибрина, их можно выявлять и фиксировать с помощью гистохимических методов. В частности, после приготовления гистологического среза, последнее с использованием метода Picro - Mallory в модификации Д.Д. Зербино - “оранжевый - красный - голубой” позволяет выявить фибрины на разных сроках его образования и в зависимости от окрашивания определять “возраст” фибрина. Практика показывает, что данный метод является существенным дополнением к гистологическому методу, так как позволяет определять ранние сроки давности повреждения от 0-6 часов (“молодых” фибринов) и до более 24-48 часов (“старых” фибринов). 
Таким образом, при экспертизе телесных повреждений, установление давности внутричерепных повреждений зависит от многих причин, которые создают значительные оценочные затруднения, к которым в первую очередь следует отнести отсутствие современных научно обоснованных единых методологических рекомендаций. По этой причине, имеющиеся научные наработки по связи морфологических изменений с установлением давности внутричерепных повреждений могут быть использованы в судебно - медицинской экспертной практике лишь как ориентировочные. В этой связи, с учетом накопленного опыта, использование сочетанного гистологического и гистохимического методов позволяет значительно повысить достоверность полученных в ходе судебно - медицинских экспертных исследований результатов.

\section{Список литературы}

1. Кошак К.В. Динамика морфологических изменений фибрина в мягких обол очках и в веществе головного мозга при острой ЧМТ,Диссертация на соискание ученной степени кандидата медицинских наук автореферат. Новосибирск 2008г

2. Медицинские Диссертации http://medical-diss.com/ medicina/ kompleksnye-morfologicheskie,i-fotometricheskie-issledovaniya-pri-sudebno-meditsinskom-ustanovlenii-davnosti-cherepnomoz\#ixzz5qtTpndMq

3. Источник:https://medbe.ru/materials/cherepno-mozgovye-narusheniya/ vnutrimozgovye-gematomypri-chmt/C medbe.ru

4. eurolab-portal ru>enciklopedia /neurologi patient/

5. journal.forens-lit.ru node 562

6. В.Г.Науменко Н.А.Митяева Гистологические и цитологические методы исследования в судебной медицине М.М.1980г стр.118-134

7. Автандилов-Проблемы патогенеза и патологоанатомической диагностики болезней в аспектах морфометрии. Москва Медицина 1984г, стр. 68-73

8. Э.Пиррс Гистохимия, Изд. Иностранной литературы Москва 1962 г. Стр.578-

9. Ю.А.Медведев Таблицы для определения сроков давности инфарктов и кровоизлияния в головном мозге /пособие для врачей/Санкт -Петербург 1997г.

10. Гистологические экспертизы 17-1315,18-0076,18-0095.18-0926 и д8

11. Brueton M.J., Breeze G.R., Stuart J. Fibrin-fibrinogen degradation products in cerebrospinal fluid. // J ClinPathol. 1976 Apr; 29(4):341-4. 590,567-568

12. Определение возраста фибрина по методу Зербина Д.Д. Lektsii.org.16-16610 htmi

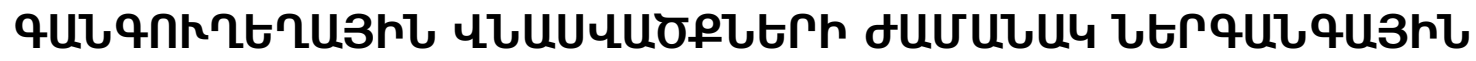

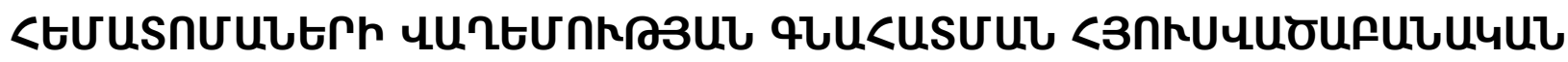

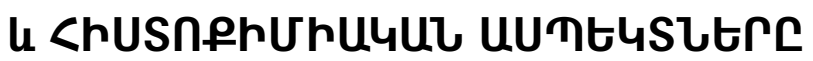

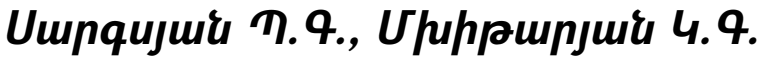

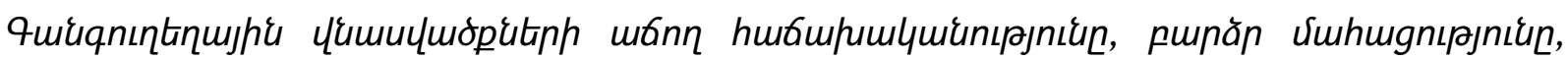

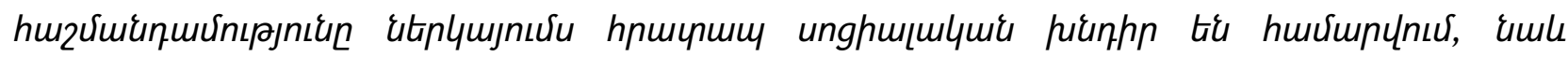

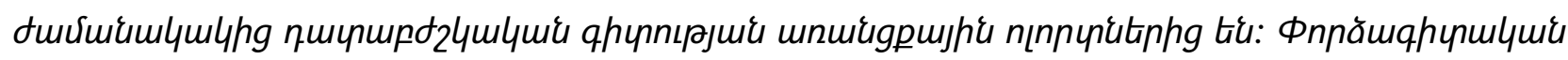

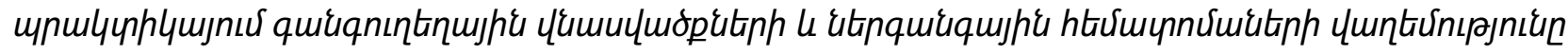

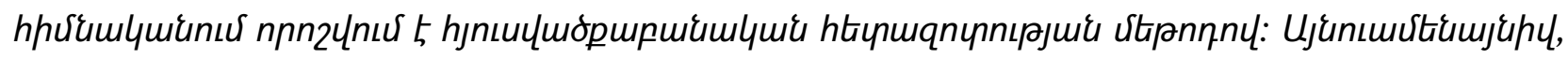




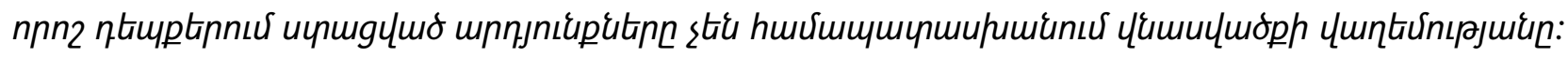

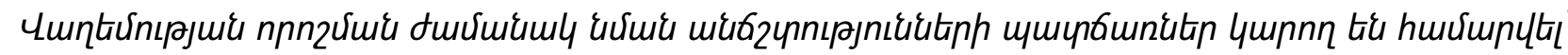

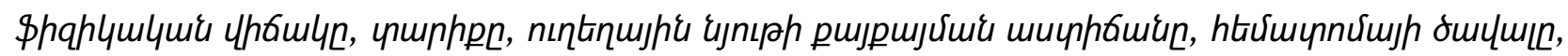

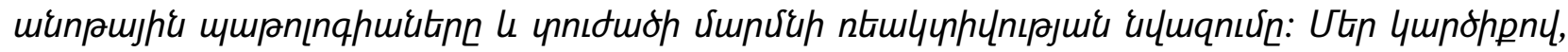

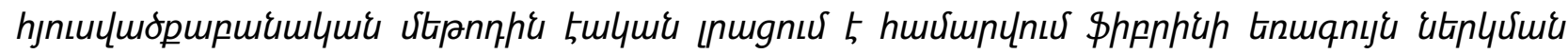

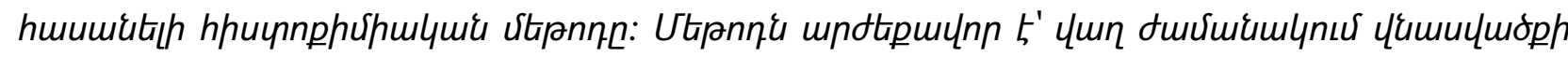

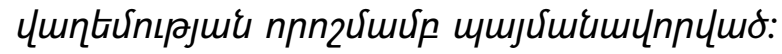

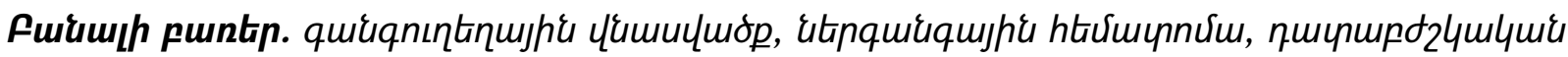

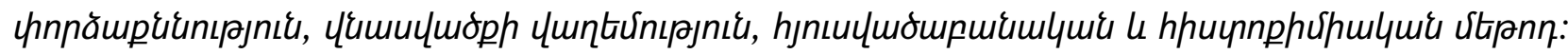

\section{HISTOLOGICAL AND HISTOCHEMICAL ASPECTS OF THE ASSESSMENT OF DETERMINATION OF THE AGE OF INTRACRANIAL HEMATOMA WITH TRAUMATIC BRAIN INJURY}

\section{Sargisyan P., Mkhitaryan K.}

The increasing frequency, high mortality and disability of traumatic brain injury is currently an urgent social problem and is considered one of the key areas of modern forensic medical science. In expert practice the prescription of traumatic brain injury and intracranial hematoma is mainly determined by histological research methods. However, in some cases, the results obtained do not correspond to the time of injury. The reasons for such inaccuracies in determining the prescription are the physical well-being, age, the degree of destruction of the brain substance, the volume of the hematoma, vascular pathologies and hyporesponsiveness of victims body. In our view, a significant addition to the histological method is the available histochemical method for tricolor staining of fibrin. The value of the method lies in the fact that the prescription of injury is determined at early date.

Keywords: traumatic brain injury, intracranial hematoma, forensic medical expertise, prescription of injury, histological and histochemical methods

Статья поступила: 06.07.2021

Принята к печати: 06.12.2021 